\title{
Moisture accumulation analyses over windowpane, based on onsite measurements in sleeping room
}

\author{
Martin Ivanov ${ }^{1, *}$ \\ ${ }^{1}$ Technical University - Sofia, FPEPM, Department:" Hydroaerodynamics and Hydraulic Machines", \\ Sofia 1000, Bulgaria
}

\begin{abstract}
The current paper presents moisture accumulation analyses over windowpane, based on onsite measurements in genuine sleeping room. During the measurements, the room was occupied with two adults and a baby, and the occupant's behaviour was not additionally modified. The examination of the results represented the generic conditions for the windowpane condensation appearance, without taking into account the window assembly properties or the building construction. The studied windowpane has visually confirmed condensation in the lower left corner. This moisture accumulation is confirmed by the obtained measurement results near the windowpane, which clearly showed lower air temperature and higher relative humidity, compared with the rest of the occupied space. Thermal images also confirm this effect, and give better interpretation of the time periods, at which the surface temperature of the windowpane is lower than the dew point temperature in the affected zone. The analysed results offer important understanding of the interference of the different indoor parameters, related to the generic conditions for windowpane condensation appearance. These results may contribute the development of numerical model, capable to predict the heat losses and the moisture accumulation processes, in such affected areas from the building envelope.
\end{abstract}

\section{Introduction}

Windows are considered as one of the most significant elements of the building envelope, since they provide the viral connection between the indoor and outdoor environment to the occupants. They are connected with two of the most substantial parameters for the indoor environment - light and aeration. But on the other hand, windows and windowpanes are responsible for largest amount of heat and energy losses from the buildings. Also, the desired by the customers and designed by the architects, percentage of window areas from the building envelope, has increased significantly during the past years [1]. Thus, the development and implementation of sustainable and energy-efficient windows and windowpanes, is crucial for the whole building industry.

\footnotetext{
*Corresponding author: $\underline{m}$ ivanov@tu-sofia.bg
} 
Poor windowpane performance leads to higher energy loss, but it is also associated with increased moisture accumulation (also known as condensation) over the inside windowpane surface. Frequently, the consequences of this may lead to mould growth and serious respiratory problems, but most often it leads simply to significant decrease of the inside air quality, at which the occupants are exposed. Furthermore, windowpane condensation is related with an increased risk for mite allergen reactions [2]. It also has strong influence on the overall dampness in the buildings, and therefore it is associated with the development of asthma symptoms in children [3]. Additionally, the windowpane condensation may be considered as an indicator for low air exchange rate in the occupied spaces [4].

The different types of windowpanes can cause different impacts over the building's energy performance. The currently designed and installed windows could have 10-times higher thermal transmittance (U-values), than building walls and other envelope elements [5]. In most of the cases, multiple layer glazed windows are installed, for better energy efficiency, and the thermal design and structural performance is regulated by standards [6]. But, the risk of condensation over the windowpane and inside the window structure, will still depend on both window properties and indoor and outdoor meteorological conditions. As suggested in [7], the air gap between the inside and outside glazing, should be aerated with outside air, to allow the windowpane to dry out, in case of excess moisture. This is applicable, especially for triple glazed windows. If such air is supplied, the drying out time is significantly reduced and condensation should rarely occur, but the U-value of the window structure is significantly lowered, and thus its energy performance.

The risk of moisture accumulation over windowpanes is higher in buildings, situated in cold and moderate climates. The assessment of that risk is performed in different ways, worldwide. For example, the Temperature Difference Ratio (TDR index) could be used. TDR index, which values ranges from 0 to 1 , is calculated as the proportion of the alteration between the indoor air temperature and the inside surface temperature of the windowpane, to the variance between the indoor air temperature and the outdoor air temperature [8]. But still, very important issue, which have significant influence over the risk of windowpane condensation, is the dynamic load, coming from the occupants in the enclosed space and their activities indoors. Similar studies are performed by the author, presented in [9] and [10], in which the influence of the inhabitants over the generic conditions for thermal bridge presence in the residence space is considered. Thus, further experimental studies in the windowpane zones are needed, especially for obtaining boundary and initial conditions for predictive numerical simulations of the related thermal process.

\section{Study aim}

The aim of the study is to analyse the moisture accumulation conditions over windowpane, in occupied residential room, by instantaneous field measurements of the indoor and outdoor climate parameters.

\section{Study methods}

The main methods in the presented work involve onsite experimental measurements of the indoor and outdoor environmental parameters, in windowpane area, with confirmed moisture accumulation zone. The condensation zone is at the lower left corner of the windowpane and is confirmed visually by the picture presented in Fig. 1. The measured parameters in the room are the air temperature, windowpane surface temperature, relative humidity and $\mathrm{CO}_{2}$ concentration, which is used as an indicator for presence of the 
inhabitants and consequently as air aeration indicator. The outdoor measured parameters are the outside air temperature and relative humidity. The windowpane surface temperature in the condensation zone is collected with infrared images, taken in random sequence, during the experiment duration. The room is used for a sleeping area and is employed by two adults and a small baby. The measurements were taken under unrestrained occupant activities, which agrees with the actual room use. The effect of the occupant behaviour, influencing the moisture accumulation conditions over the windowpane, will be considered later.
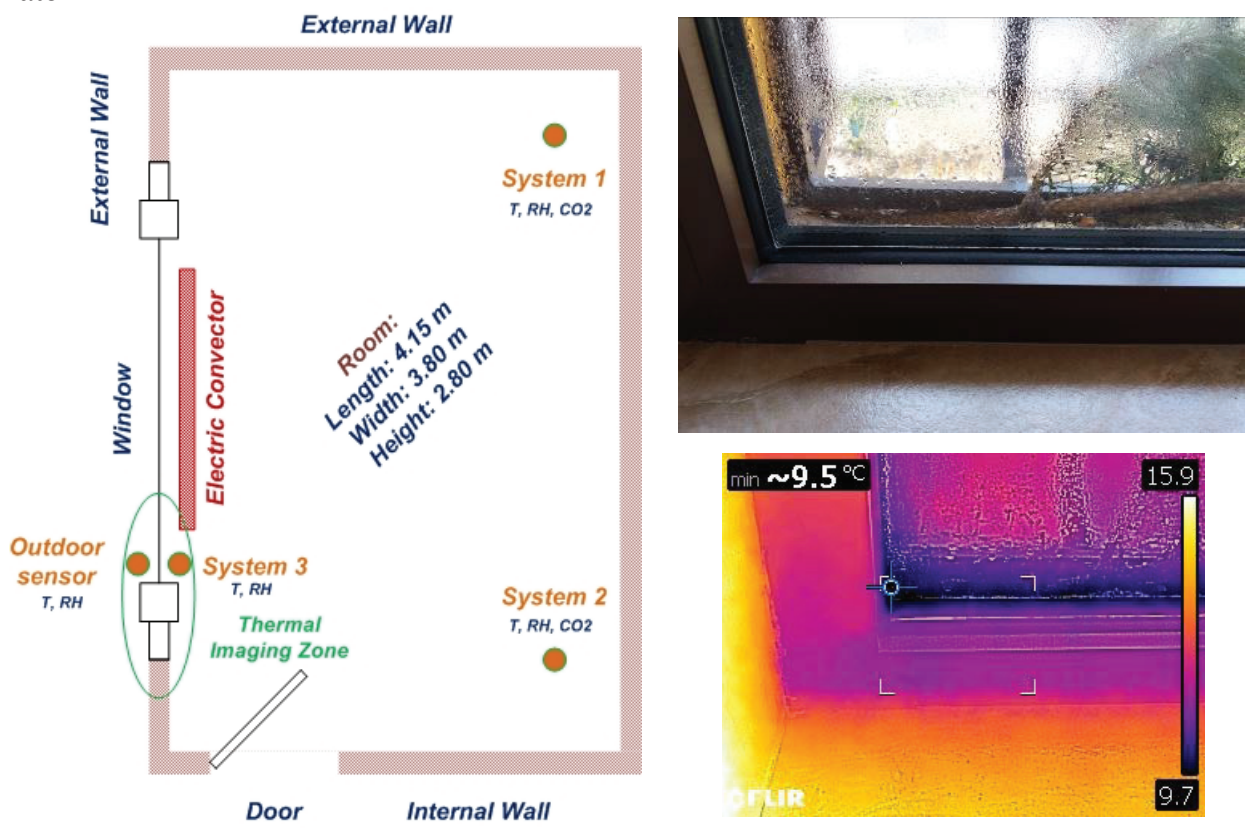

Fig. 1. Experimental area plan with measurement points and moisture accumulation zone

The measurements were done in the winter season, with interval of 6 days and 6 nights, which resembles to a short-term experiment. The winter season was chosen, since the windowpane condensation is more likely to occur in the cold outside temperature, and the corresponding parameters are better recognised and taken in the heating period of the year. The measurements were taken from 19:00h on 29. January 2020 (Wednesday), till 15:20h on 04. February 2020 (Tuesday). This period was divided into two parts, i.e. two experimental modes. In the first part, from the beginning till 23:30h on 01. February 2020 (Saturday), the family occupied the room normally, with no restrictions of the activities. For the second part, from 23:30h on 01. February 2020 (Saturday), the family left the room till the end of the experimental measurements. The first period is called for simplicity "full load period", and the second - "no-load period". During the no load period, the window was not opened, the heating system was turned off, and the access to the room was restricted. Only one operator was taking the infrared images, at the corresponding time. Thus, with these two experimental modes, the moisture accumulation could be studied under two extreme conditions, considering the room occupant load.

The measurements of the ambient parameters were taken by HOBO data loggers, made by ONSET Company, enabling long time records of the air temperature, relative humidity and $\mathrm{CO}_{2}$ concentration in the area. The data was collected for every minute in the corresponding measurement points, for the complete time period. FLIR C3 infrared thermal camera is used, to capture the surface temperature of the lower left side of the windowpane. 
Descriptive analyses of all attained results are offered in terms of tables and graphics. Besides the measured variables, the dew point temperature is calculated and analysed in the condensation zone. The calculation process is further described in [10]. It is believed that, this analysis provides valuable understanding of the generic conditions for windowpane condensation appearance, without considering the windowpane structure and properties. The information will be used for initial and boundary conditions for the development of CFD (Computational Fluid Dynamics) based numerical model. This model will be able to predict the risk of condensation in windowpane areas.

\section{Experimental design and instrumentation}

The experimental room layout and the study points are shown on Fig. 1. The area is part of a house, located in the western part of Sofia, Bulgaria. The alignment is South, and the window is in South. The flooring is $16 \mathrm{~m}^{2}$, and the height is $2.80 \mathrm{~m}$, which implies 44.80 $\mathrm{m}^{3}$ of air volume. This area is a sleeping room and is occupied by two adults and a small baby. Electric convector, located under the window, heats up the room to support the normal $20-21^{\circ} \mathrm{C}$ for the entire full load period. For the no load period, the convector was turned off.

The window size is $1.80 \mathrm{~m}$ by $1.25 \mathrm{~m}$, and only the right half side is able to open, and the zone with the visible condensation is fixed. The frame is made of aluminium, with approximate size $6 \mathrm{~cm}$ by $6 \mathrm{~cm}$. The frame does not have disconnected thermal bridge. The glazing is double, with $5 \mathrm{~mm}$ thickness of clear uncoated (not k-type) glasses, and $10 \mathrm{~mm}$ space between them.

The data loggers inside, were spread among three systems, the position of which are shown on Fig. 1. In all of them, the air temperature and relative humidity was logged, and System 1 and System 2 allowed also the $\mathrm{CO}_{2}$ measurements. The height from the floor was about one meter. The positions of the devices were designated to be far from of the occupants' breathing zones and at distance from the walls, in correlation with the measurement standards.

System 3 logger was installed in very closed proximity to the windowpane's left corner. Thus, the adjacent indoor air parameters were measured, which are affected by the moisture accumulation zone. This is the zone, where the thermal images were taken. When this was done by the operator, the System 3 logger was gently detached from the position, for few second, and then left back on position. The Outdoor sensor, which recorded the outdoor air temperature and relative humidity, was placed on the other side of System 3, near the windowpane outer surface.

\section{Results and discussion}

The entire measurement data was analysed and is revealed down in terms of graphics. The presented values, of the temperatures and relative humidity distribution, explain the instantaneous fundamental conditions for the moisture accumulation over the windowpane surface.

The outside air temperature and relative humidity are presented on Fig. 2, for the whole study duration. The average measured temperature is $8.76{ }^{\circ} \mathrm{C}\left(\mathrm{SD} 4.20{ }^{\circ} \mathrm{C}\right)$ for the entire experimental period, which is higher than the normal statistical values for that month in Bulgaria. The minimum value is $0.50{ }^{\circ} \mathrm{C}$, and the maximum is $23.42{ }^{\circ} \mathrm{C}$, which is not normal for January and February in Bulgaria. 


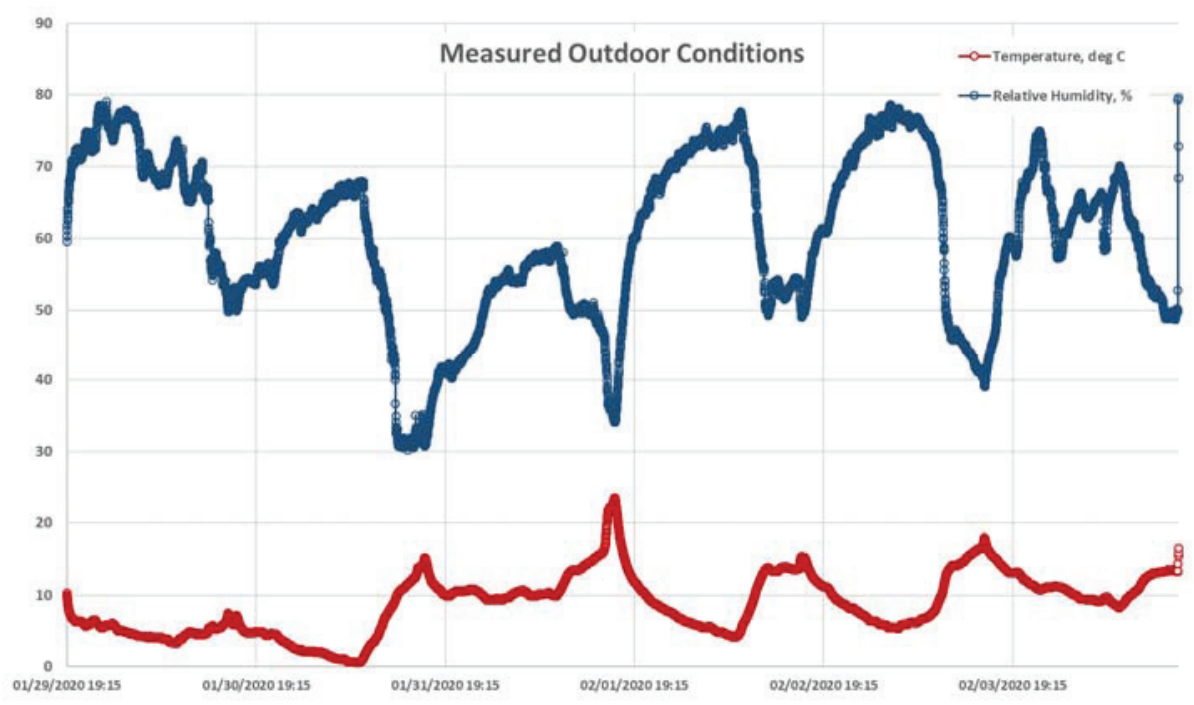

Fig. 2. Outside atmospheric conditions for the entire measurement period

The recorded average relative humidity is $60.29 \%$ (SD $11.61 \%$ ), with minimum of $30.22 \%$, and maximum of $79.09 \%$. The rise and the reduction of the outside air temperature leads to the changes of the relative humidity, which happens distinctively during the day and night periods. Throughout the nights, the outside air temperature is lower, and the relative humidity is higher, and it is expected that these deviations will strongly influence the heat transfer through the windowpane, and thus the moisture accumulation zone. It should be mentioned that the heat transfer is also affected by the wind speed and sunlight intensity during the period, which are not measured.

The obtained room environment data is presented on Fig. 3 and Fig. 4 and is summarized in Table 1. The different graphs give more comprehensive visualization of the measured results for the two room locations. The calculated dew point temperature is represented in yellow line. The full load and no-load periods are distinctively seen.

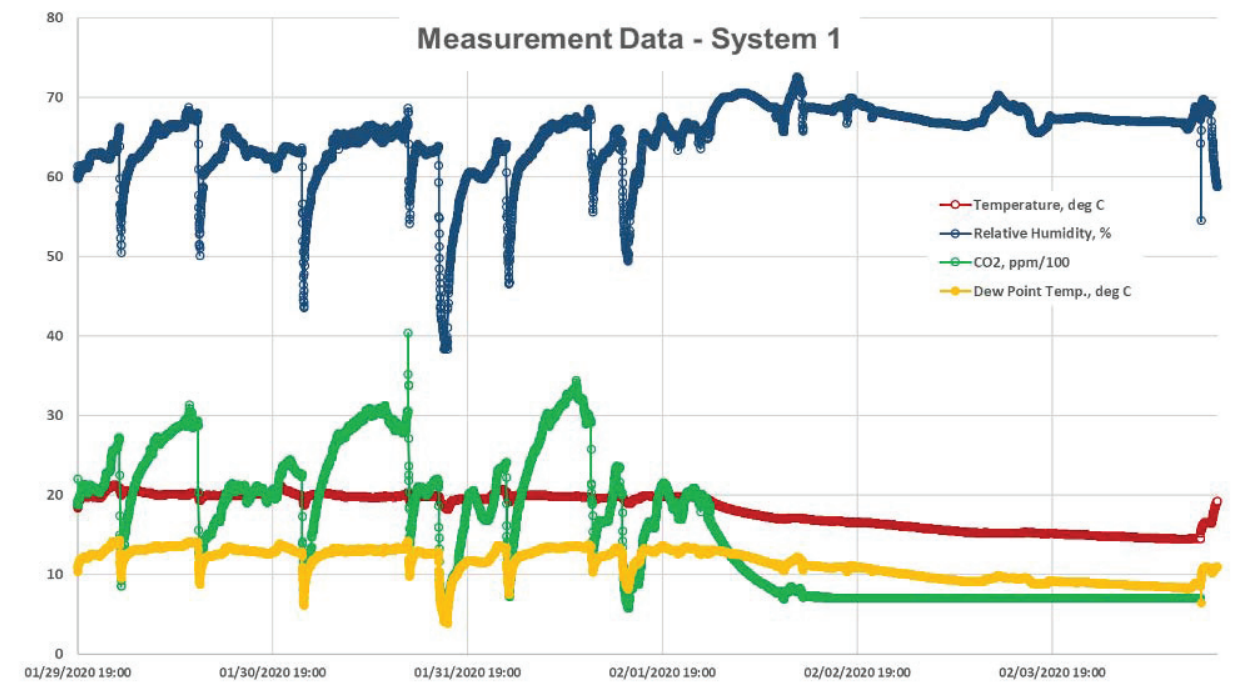

Fig. 3. Obtained room environment data, for System 1 


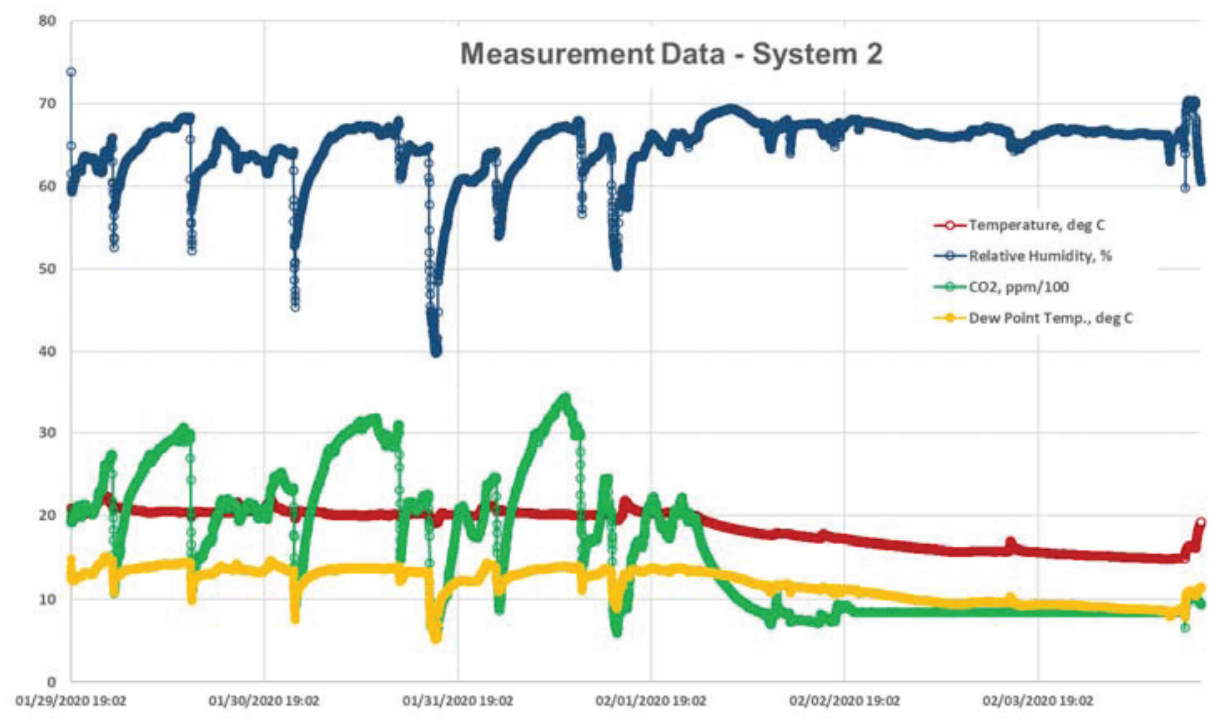

Fig. 4. Obtained room environment data, for System 2

Table 1. Summarised room environment data for System 1, System 2 and System 3

\begin{tabular}{|c|c|c|c|c|c|c|c|c|}
\hline \multirow{2}{*}{ Indoor condition } & \multicolumn{5}{|c|}{ Full load period } & \multicolumn{5}{c|}{ No-load period } \\
\cline { 2 - 9 } & min & max & average & SD & min & max & average & SD \\
\hline System 1 - Temp., ${ }^{\circ} \mathrm{C}$ & 18.22 & 21.29 & 19.92 & 0.39 & 14.43 & 19.65 & 16.01 & 1.25 \\
\hline System 2 - Temp., ${ }^{\circ} \mathrm{C}$ & 19.08 & 22.32 & 20.39 & 0.44 & 14.84 & 20.15 & 16.50 & 1.31 \\
\hline System 3 - Temp., ${ }^{\circ} \mathrm{C}$ & 14.15 & 28.64 & 18.58 & 1.50 & 13.19 & 20.15 & 15.01 & 1.38 \\
\hline System 1 - RH, \% & 38.33 & 68.76 & 62.68 & 4.44 & 54.51 & 72.54 & 67.86 & 1.48 \\
\hline System 2 - RH, \% & 39.85 & 73.84 & 63.31 & 4.16 & 59.81 & 70.43 & 66.86 & 1.14 \\
\hline System 3 - RH, \% & 34.71 & 80.32 & 68.26 & 7.78 & 58.12 & 78.66 & 71.53 & 4.21 \\
\hline S1 - Dew Point Temp., ${ }^{\circ} \mathrm{C}$ & 3.83 & 14.36 & 12.57 & 1.40 & 6.45 & 13.13 & 10.09 & 1.33 \\
\hline S2 - Dew Point Temp., ${ }^{\circ} \mathrm{C}$ & 5.17 & 15.12 & 13.17 & 1.22 & 7.87 & 13.50 & 10.34 & 1.36 \\
\hline S3 - Dew Point Temp., ${ }^{\circ} \mathrm{C}$ & 3.13 & 15.64 & 12.51 & 1.52 & 7.87 & 13.10 & 9.89 & 1.39 \\
\hline System 1 - $\mathrm{CO}_{2,}$ ppm & 547 & 4036 & 2162 & 629 & 698 & 2014 & 795 & 236 \\
\hline System 2 - CO $2, \mathrm{ppm}$ & 565 & 3431 & 2210 & 631 & 657 & 2027 & 905 & 217 \\
\hline
\end{tabular}

For the full load period, the average temperature measured by System 1 is $19.92{ }^{\circ} \mathrm{C}$ (SD $0.39^{\circ} \mathrm{C}$ ). The minimum and maximum values are $18.22^{\circ} \mathrm{C}$ and $21.29^{\circ} \mathrm{C}$, respectively. The average relative humidity is $62.68 \%$ (SD $4.44 \%$ ), with minimum and maximum values of 
$38.33 \%$ and $68.76 \%$, respectively. For the same period, the average temperature recorded by System 2 is $20.31{ }^{\circ} \mathrm{C}\left(\mathrm{SD} 0.44{ }^{\circ} \mathrm{C}\right.$ ). The minimum and maximum values are $19.08{ }^{\circ} \mathrm{C}$ and $22.32{ }^{\circ} \mathrm{C}$, respectively. The average relative humidity, according to System 2, is 63.31 $\%$ (SD $4.16 \%$ ), with minimum and maximum values of $39.85 \%$ and $73.84 \%$, respectively. In terms of $\mathrm{CO}_{2}$ measurements, the average values registered with both systems are high $2162 \mathrm{ppm}$ and $2210 \mathrm{ppm}$. This suggests decreased aeration rate in the room and is prerequisite for lower indoor air quality.

For the no-load period, the average temperature measured by System 1 is $16.01{ }^{\circ} \mathrm{C}$ (SD $1.25^{\circ} \mathrm{C}$ ). The minimum and maximum values are $14.43{ }^{\circ} \mathrm{C}$ and $19.65^{\circ} \mathrm{C}$, respectively. The average relative humidity is $67.86 \%$ (SD $1.48 \%$ ), with minimum and maximum values of $54.51 \%$ and $72.54 \%$, respectively. For the same period, the average temperature recorded by System 2 is $16.50{ }^{\circ} \mathrm{C}\left(\mathrm{SD} 1.31{ }^{\circ} \mathrm{C}\right)$. The minimum and maximum values are $14.84{ }^{\circ} \mathrm{C}$ and $20.15^{\circ} \mathrm{C}$, respectively. The average relative humidity, according to System 2, is 66.86 $\%$ (SD $1.14 \%$ ), with minimum and maximum values of $59.81 \%$ and $70.43 \%$, respectively. For the $\mathrm{CO}_{2}$ measurements, the average values registered with both systems are still high 2014 ppm and 2027 ppm, nevertheless that there are no occupants in the room. This confirms that there is decreased aeration rate in the room, even decreased infiltration and exfiltration, which is prerequisite for lower indoor air quality.

The presented data above demonstrates rather high consistency in the indoor air temperature and relative humidity spreading in the studied area. The values measured by System 2 are relatively higher in average, because the location of the system is adjacent to the inside wall and close the entrance of the room. But, the non-perfect mixing and the decreased aeration rate in fairly large periods of time, makes the difference of the relative humidity distribution. However, the obtained parameters are in the comfortable range for the indoor environment requirements in winter season.

The air temperature and relative humidity near the windowpane, measured by System 3, are presented on Fig. 5 and again summarized in Table 1. For the full load period, the average temperature measured by System 3 is $18.58{ }^{\circ} \mathrm{C}\left(\mathrm{SD} 1.50{ }^{\circ} \mathrm{C}\right)$. The minimum and maximum values are $14.15{ }^{\circ} \mathrm{C}$ and $28.64{ }^{\circ} \mathrm{C}$, respectively. The average relative humidity is $68.26 \%$ (SD $7.78 \%$ ), with minimum and maximum values of $34.71 \%$ and $80.32 \%$, respectively.

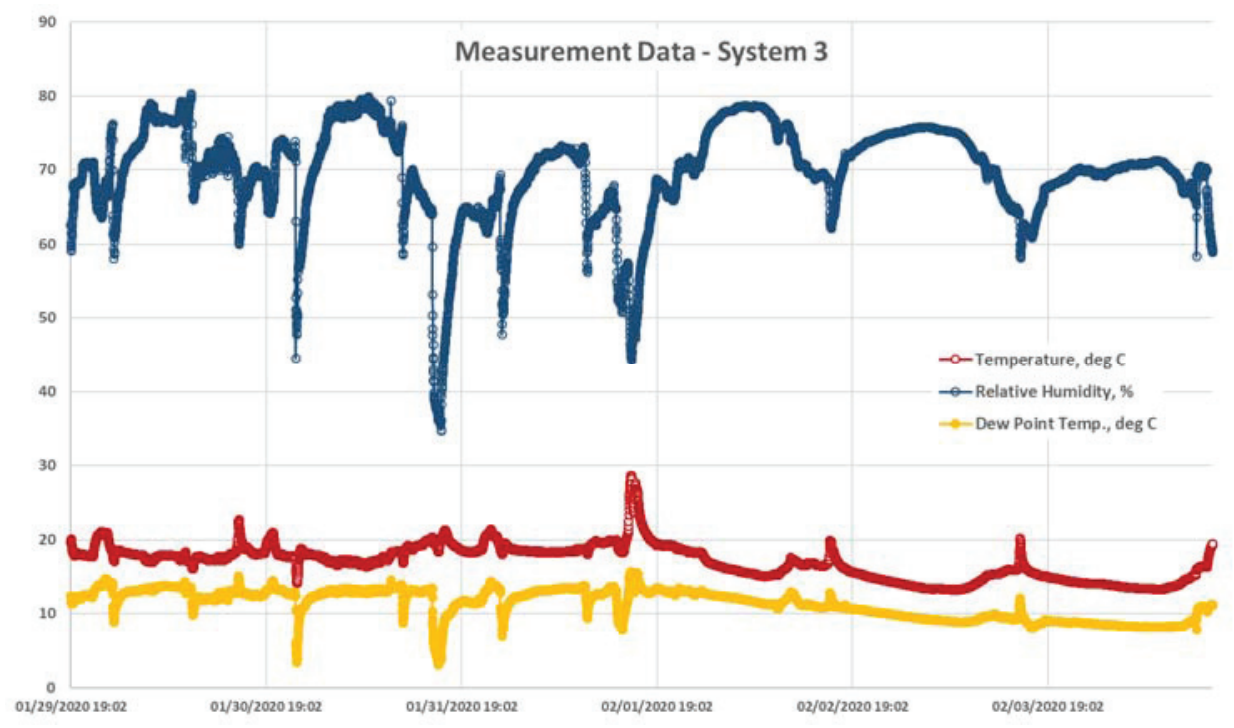

Fig. 5. Obtained indoor environment data in the moisture accumulation zone, System 3 
For the no-load period, the average temperature measured by System 3 is $15.01{ }^{\circ} \mathrm{C}$ (SD $1.38^{\circ} \mathrm{C}$ ). The minimum and maximum values are $13.19^{\circ} \mathrm{C}$ and $20.15^{\circ} \mathrm{C}$, respectively. The average relative humidity is $71.53 \%$ (SD $4.21 \%$ ), with minimum and maximum values of $58.12 \%$ and $78.66 \%$, respectively. The results for the windowpane lower left region clearly show expressively lower air temperature and expressively higher relative humidity, compared with the rest of the studied room. This is predisposition for the moisture accumulation problems over the windowpane surface. During the full load experiment, the relative humidity fluctuates in wider span and has higher peak values, due to the presence of the occupants and their aeration activities.

As mentioned above, the dew point temperature is also analysed for the two experimental periods, in the three measurement locations. As expected, the dew point temperature maximum value is highest in the windowpane area, for the full load experiments, and the corresponding value is $15.64^{\circ} \mathrm{C}$. This value is considered as potentially high. For the same experimental mode, the minimum and average values are $3.13{ }^{\circ} \mathrm{C}$ and $12.51{ }^{\circ} \mathrm{C}\left(\mathrm{SD} 1.52^{\circ} \mathrm{C}\right)$, respectively.

The bias conditions for the moisture accumulation over the windowpane are confirmed by the thermal imaging data, shown in Table 2. The presented values are the minimum measured temperature in the focus area, located at the lower left corner of the windowpane (Fig. 1). There are 15 measurements done, during the full load experiment, taken in random sequence.

Table 2. Minimal values of the surface temperatures in the windowpane moisture zone

\begin{tabular}{|c|c|c|c|c|}
\hline 1/29/20 19:00h & 1/29/20 21:00h & 1/30/20 09:30h & 1/30/20 12:30h & $1 / 30 / 2022: 30 h$ \\
\hline $14.0^{\circ} \mathrm{C}$ & $13.3^{\circ} \mathrm{C}$ & $10.2^{\circ} \mathrm{C}$ & $11.9^{\circ} \mathrm{C}$ & $9.4^{\circ} \mathrm{C}$ \\
\hline 1/31/20 09:30h & 1/31/20 12:30h & 1/31/20 15:30h & 1/31/20 21:00h & 1/31/20 23:30h \\
\hline $9.3^{\circ} \mathrm{C}$ & $12.0^{\circ} \mathrm{C}$ & $15.5^{\circ} \mathrm{C}$ & $13.6^{\circ} \mathrm{C}$ & $13.6^{\circ} \mathrm{C}$ \\
\hline 2/01/20 09:00h & 2/01/20 13:30h & 2/01/20 21:30h & 2/01/20 23:30h & 2/02/20 18:00h \\
\hline $13.1^{\circ} \mathrm{C}$ & $16.1^{\circ} \mathrm{C}$ & $12.6^{\circ} \mathrm{C}$ & $12.3^{\circ} \mathrm{C}$ & $13.5^{\circ} \mathrm{C}$ \\
\hline
\end{tabular}

For further analyses on the moisture accumulation mechanism, on Fig. 6 are presented the thermal imaging results, in comparison with the obtained values of the air temperature form System 3. The surface temperature values obtained by the camera are significantly lower than the one, measured with the temperature logger. One explanation is because, the logger detects the air temperature in very close distance with the moisture accumulation zone over the windowpane, rather than the direct surface temperature, registered by the infrared camera. Also, the device is affected by the radiant heat from the sunlight, during the day periods. Nevertheless, the heat loss through the affected windowpane zone is clearly demonstrated, and the corresponding environmental parameters are registered.

Large time intervals are also seen on Fig. 6, in which the dew point temperature is higher than the surface temperature of the windowpane corner. For the full load experiment, these periods are mainly during the nights, or in the early mornings, when the room is occupied, and the outside temperatures are low. These are the periods with the highest registered $\mathrm{CO}_{2}$ concentrations and highest values of the relative humidity indoors. Apparently, in these peak periods, condensation over the windowpane surface is anticipated. 


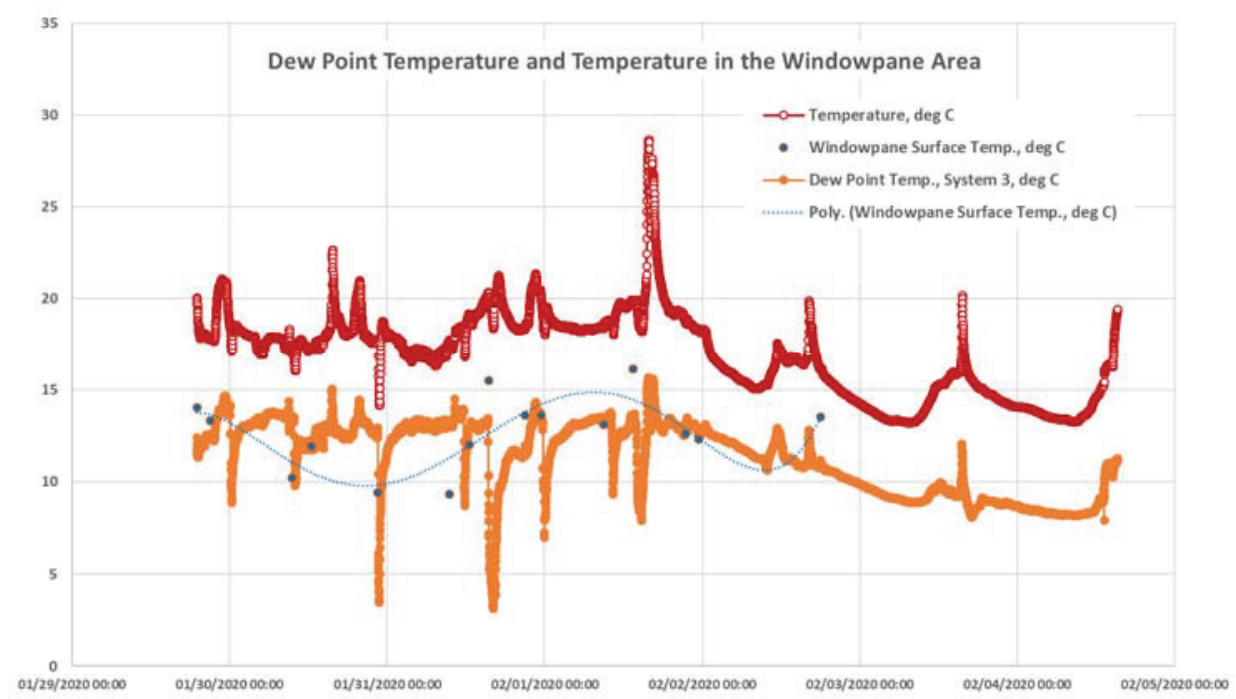

Fig. 6. Assessment of the measured data in the moisture accumulation zone from the windowpane

For the no-load period, the air temperature and the dew point temperature are lower, and the tendency of the surface temperature of the windowpane is to reach the air temperature in the closed proximity, since there are no additional heat sources in the room. During this period, the possibility for condensation are also high, because there were no additional aeration measures taken by the occupants, after leaving the room. The infiltration and exfiltration levels are low for the studied enclosed environment. Thus, the occupant presence and behaviour are one of the most significant issues for the condensation effect over the windowpane surface, in this study.

\section{Conclusions}

In the presented study, moisture accumulation analyses over windowpane, based on field experimental measurements in sleeping room, was performed. The analyses of the results represented the generic conditions for the windowpane condensation appearance, without considering the window assembly properties or the building structure.

The measurement data confirms decent homogeneity in the distribution of the indoor environment parameters, which assists the proper identification of the moisture accumulation mechanism. The room air temperature is in the comfortable range for the wintertime. However, the average relative humidity and $\mathrm{CO}_{2}$ are considerably high, especially for two adults and a baby.

The studied windowpane has visually confirmed condensation in the lower left corner. This moisture accumulation is confirmed by the obtained measurement results near the windowpane, which clearly showed lower air temperature and higher relative humidity, compared with the rest of the occupied space. Thermal images also confirm this effect, and give better interpretation of the time periods, at which the surface temperature of the windowpane is lower than the dew point temperature in the affected zone.

The analysed results offer important understanding of the interference of the different indoor parameters, related to the generic conditions for windowpane condensation appearance. These results may contribute the development of dynamic numerical model, capable to predict the heat losses and the moisture accumulation processes, in such affected areas from the building envelope. 
The presented study is supported by the National Science Fund at the Ministry of Education and Science of Bulgaria, under the activities of: "Competition for financial support for projects of junior basic researchers and postdocs - 2018", with Contract -06-27/4, entitled: "Numerical assessment of effective measures for prevention of moisture accumulation on external walls with thermal bridge, in residential rooms without organized ventilation".

\section{References}

[1] E. C. Ochoa, M. Aries, E. van Loenen and J. Hensen, "Considerations on design optimization criteria for windows providing low energy consumption and high visual comfort", Applied Energy 95: 238-45, https://doi.org/10.1016/j.apenergy.2012.02.042, (2012)

[2] C. Luczynska, J. Sterne, J. Bond, H. Azima and P. Burney, "Indoor factors associated with concentrations of house dust mite allergen, Der $p$ 1, in a random sample of houses in Norwich, UK", Clin Exp Allergy 28:1201-9, (1998)

[3] E. Ronmark, E. Jonsson, T. Platts-Mills and B. Lundback, "Different pattern of risk factors for atopic and nonatopic asthma among children-report from the Obstructive Lung Disease in Northern Sweden Study", Allergy 54:926-35, (1999)

[4] C. Janson, P. Kalm-Stephens, T. Foucard, D. Norback, K. Alving and S. L. Nordvall, "Exhaled nitric oxide levels in school children in relation to IgE sensitisation and windowpane condensation", Respiratory Medicine 99: 1015-1021, Elsevier, (2005)

[5] B. Subich, A. Ugovsek, N. Starman, U. Tatic, A. Kovacic and G. Fajdiga, "Influence of glued-in reinforcement profiles on the thermal characteristics of wooden window profiles", Procedia Structural Integrity 13: 503-510, Elsevier, (2018)

[6] ISO 15099, "Thermal performance of windows, doors and shading devices - Detailed calculations", (2003)

[7] S. Asphaug, B. Time, S. Uvsløkk, D. Plsek and A. Gustavsen, "Moisture in Multi-Layer Windows", Energy Procedia 78: 2482 - 2487, (2015)

[8] S. Park, S. Koo, J. Lim, Y. Seong and S. Song, "Condensation resistance evaluation of a double-sliding window system for apartment buildings", Procedia Engineering 146: 60 68, Elsevier, (2016)

[9] M. Ivanov, "Instantaneous field measurements of thermal bridge parameters in ground floor residential room", Proc. "8th Int. Conf. on Thermal Equipment, Renewable Energy and Rural Development - TE-RE-RD 2019”, Web of Conf., doi: 10.1051/e3sconf/201911201016, (2019)

[10] M. Ivanov, "Dew point temperature analyses in ground floor residential room with existing thermal bridge", Proc. "8th Int. Conf. on Thermal Equipment, Renewable Energy and Rural Development - TE-RE-RD 2019", Web of Conf., doi: 10.1051/e3sconf/201911201017, (2019) 